\begin{tabular}{|l|l|l|}
\hline \multicolumn{2}{|c|}{ PublisherInfo } \\
\hline \hline PublisherName & $:$ & BioMed Central \\
\hline \hline PublisherLocation & $:$ & London \\
\hline \hline PublisherImprintName & $:$ & BioMed Central \\
\hline \hline
\end{tabular}

\title{
DNA sequences associated with chromatin proteins
}

\begin{tabular}{|l|l|l||}
\hline \multicolumn{2}{|c|}{ ArticleInfo } \\
\hline \hline ArticleID & $:$ & 3628 \\
\hline \hline ArticleDOI & $:$ & $10.1186 /$ gb-2000-1-2-reports0051 \\
\hline \hline ArticleCitationID & $:$ & reports0051 \\
\hline \hline ArticleSequenceNumber & $:$ & 25 \\
\hline \hline ArticleCategory & $:$ & Paper report \\
\hline \hline ArticleFirstPage & $:$ & 1 \\
\hline \hline ArticleLastPage & $:$ & 4 \\
\hline \hline & & RegistrationDate : 2000-5-4 \\
ArticleHistory & $:$ & Received \\
& $: 2000-5-4$ \\
\hline ArticleCopyright & $:$ & BioMed Central Ltd2000 \\
\hline \hline ArticleGrants & $:$ & \\
\hline \hline
\end{tabular}




\begin{tabular}{|l|l|l|}
\hline ArticleContext & $:$ & 130591122 \\
\hline
\end{tabular}

\section{Michaela Torkar}

\section{Abstract}

Specific DNA targets of chromatin-associated factors have been enzymatically marked in order to identify loci that are regulated at the level of chromatin organization in eukaryotes.

\section{Significance and context}

Throughout differentiation, cells must activate some genes and silence others, and these states must be maintained during replication. Nuclear organization and packaging of DNA into chromatin underpins this level of regulation, called epigenetics. The identification of chromatin-associated proteins and their target DNA sites is therefore crucial for an understanding of the molecular mechanisms underlying these regulatory processes. Existing techniques to identify protein-DNA interactions, such as chromatin immunoprecipitation and immunofluorescence, are technically difficult and are potentially subject to artifacts. Conventional footprinting, another technique to identify protein-DNA interactions, depends on direct binding of transcription factors to specific DNA sequences. But key molecules involved in epigenetic phenomena are chromatin-associated proteins that do not always associate directly with DNA. It has therefore proved extremely difficult to identify their targets in vitro. This may be because they only recognize DNA that is already complexed with other proteins. One such factor, implicated in epigenetic phenomena in Drosophila, is the highly conserved heterochromatin protein 1 (HP1). It does not directly bind DNA but is predominantly associated with heterochromatic (highly condensed and repetitive) chromosomal regions, which are thought to have a silencing effect on gene expression. The authors describe a novel in vivo assay that has identified the DNA sequences that are (or have been) targeted by HP1 before, or at the time of, analysis.

\section{Key results}

Escherichia coli DNA adenine methyltransferase (Dam), which catalyzes methylation of adenine, was used as a reporter enzyme fused to Drosophila HP1. The fusion construct was transfected into Drosophila cell lines or used to generate transgenic fly lines. HP1 became integrated into the chromatin structure and directed the Dam methyltransferase to HP1-associated DNA sequences. These sequences were subsequently marked by adenine methylation. Because methylation of adenine does not normally occur in eukaryotes, sites of Dam methylation could be mapped using methylation-specific antibodies or restriction enzymes. The authors show that HP1 guided the Dam enzyme to heterochromatic loci in vivo. 
Previously unidentified potential HP1 targets included the histone gene-cluster repeat, which is thought to have heterochromatic features although located in euchromatin, as well as the rDNA repeat. The new technique may allow genome-wide mapping of DNA sequences targeted by chromatin-associated factors in various eukaryotes.

\section{Methodological innovations}

The new technique, called DamID (for Dam identification), was first tested using the yeast regulator protein Gal4 as the fusion partner. The complex was successfully targeted to inserted Gal4-binding sites in the genome of a transgenic Drosophila line. Although Dam has an intrinsic DNA-binding activity (resulting in some 'background' adenine methylation in the absence of the fused chromatin protein), targeting of the enzyme led to a tenfold increase of methylation in the vicinity of DNA-binding sites of the Dam fusion partner. This enrichment was sufficient for positive identification of target sequences. The technique was applied to cell-culture systems and the whole organism, which was possible because expression of the bacterial enzyme does not seem to affect Drosophila development. A PCR-based assay allowed sensitive quantification of protein-DNA interactions.

\section{Links}

The paper is accompanied by a News and Views article accessible to subscribers through the Nature Biotechnology website. Useful links to many research groups working in the field of epigenetics, as well as structural models, can be found on Nucleosome and chromatin pages.

\section{Conclusions}

This new approach provides a direct and sensitive method for identifying DNA sequences associated with chromatin-protein complexes. It opens the way to more detailed in vivo studies of factors previously examined in more artificial systems. The authors discuss the potential of the DamID technique for genome-wide analysis of DNA-protein interactions, for example by using Dam-methylated DNA regions as probes for screening microarrays.

\section{Reporter's comments}


At present, most methods for the identification of DNA-protein complexes have clear limitations as they depend on a strong interaction between the protein and the DNA that can withstand the nucleases or chemicals used for detection. The assay described in this paper does not require cells to be treated with external agents and enables DNA targets to be identified following enzymatic modification in vivo. As the Dam enzyme leaves a 'methylation fingerprint' where the attached regulatory factor has contacted the DNA, temporary as well as stable interactions can be monitored. DamID will have important implications for the characterization of the many unidentified proteins functionally associated with different levels of chromatin structure.

\section{Table of links}

Nature Biotechnology

Nucleosome and chromatin pages

\section{References}

1. Steensel B van, Henikoff S: Identification of in vivo DNA targets of chromatin proteins using tethered Dam methylase. Nat Biotechnol. 2000, 18: 424-428. 1087-0156 